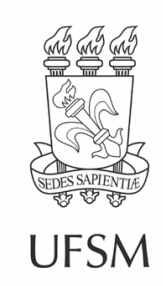

\title{
Artigos
}

\section{As zonas de vida baseadas em condições bioclimáticas no estado do Ceará, Brasil}

\author{
The life zones based on bioclimatic conditions in Ceará state, Brazil
}

\author{
Tiago de Souza Ferreira ${ }^{\oplus}$, Andressa Tres ${ }^{\oplus}$, \\ Bruna Kovalsyki ${ }^{\oplus}$, João Francisco Labres dos Santos ${ }^{\oplus}$, \\ Alexandre França Tetto ${ }^{\oplus}$, Ronaldo Viana Soares ${ }^{\ominus}$, \\ Willian Thomaz Wendling ${ }^{\oplus}$, Antônio Carlos Batista ${ }^{\oplus}$
}

'Universidade Federal do Paraná, Curitiba, PR, Brasil

\section{RESUMO}

A definição das zonas de vida de Holdridge é uma ferramenta útil para o planejamento da gestão territorial dos recursos naturais, bem como para subsidiar a elaboração de estratégias e políticas públicas que resultem na definição de áreas prioritárias para conservação e uso sustentável das florestas. Desse modo, o presente estudo teve por objetivo identificar e descrever as zonas de vida que ocorrem no estado do Ceará com base no modelo de Holdridge. Para esse propósito, foram utilizados dados de precipitação anual, biotemperatura e relação de evapotranspiração potencial. Os resultados indicaram que, embora o estado do Ceará esteja majoritariamente sob a influência de um macroclima semiárido, apresenta um espaço geográfico heterogêneo, no qual ocorrem diferentes zonas de vida associadas à diversidade bioclimática. A variável bioclimática mais importante para a classificação das zonas de vida foi a relação de evapotranspiração potencial, que representa a quantidade de água que é transferida para a atmosfera em relação a quantidade de água que é precipitada em determinado local. A classificação climática de Holdridge identificou oito zonas de vida em que todas pertencem à faixa latitudinal tropical e abrangem faixas altitudinais basais ( $90,04 \%$ do território cearense) e premontanas $(9,96 \%)$, que variam em termos de umidade, desde florestas muito secas até florestas úmidas. A zona de vida mais extensa compreende as áreas de transição entre floresta muito seca e floresta seca tropical basal, ocupando $64.825,69 \mathrm{~km}^{2}$, que recobre $43,54 \%$ da área total do estado.

Palavras-chave: Holdridge; Classificação; Clima; Vegetação 


\section{ABSTRACT}

The Holdridge life zone approach is a useful tool for planning the territorial management of natural resources as well as for supporting the development of strategies and public policies that result in the definition of priority areas for conservation and sustainable use of forests. Thus, in the present study, we aimed to identify and describe the life zones that occur in the state of Ceará based on the Holdridge model. For this purpose, we used data on annual precipitation, biotemperature and potential evapotranspiration ratio. The results indicated that, although the state of Ceará is mostly under the influence of a semi-arid macroclimate, it presents a heterogeneous geographic space, in which different life zones associated with bioclimatic diversity occur. The most important bioclimatic variable for the classification of life zones was the potential evapotranspiration ratio, which represents the amount of water that is transferred to the atmosphere in relation to the amount of water that is precipitated in a given location. The Holdridge climatic classification identified eight life zones, all located in the tropical latitudinal zone and basal (90.04\% of the Ceará territory) and premontane $(9.96 \%)$ altitudinal zones, which vary, in terms of humidity, from very dry forests to humid forests. The most extensive life zone comprises the transition areas between very dry forest and basal tropical dry forest, occupying $64,825.69 \mathrm{~km}^{2}$, which covers $43.54 \%$ of the Ceará territory.

Keywords: Holdridge; Classification; Climate; Vegetation

\section{INTRODUÇÃO}

O zoneamento ecológico de um espaço geográfico é uma ferramenta chave que permite reconhecer a heterogeneidade ambiental e classificar unidades ecológicas homogêneas (LUGO et al., 1999). Dentre as variáveis ambientais com maior utilização no mapeamento de unidades ecológicas, destaca-se o clima, uma vez que as comunidades de plantas e animais, bem como as propriedades do solo são fortemente controladas pelas condições climáticas predominantes (HOLDRIDGE, 2000).

O clima pode ser entendido como o conjunto de condições meteorológicas que incidem sobre determinado local ou região (ISAAC; BOURQUE, 2001). Dado que o clima pode variar em escala espacial e temporal, compreender o seu funcionamento tratase de uma tarefa bastante complexa (LUGO et al., 1999; ISAAC; BOURQUE, 2001; TATLI; DALFES, 2016). Sendo assim, para superar tal complexidade, uma estratégia eficaz é a categorização do clima em subclasses (LUGO et al., 1999).

Sob essa perspectiva, o modelo de zonas de vida de Holdridge (HOLDRIDGE, 2000) tem se destacado como um dos melhores métodos disponíveis para classificar 
os padrões de biodiversidade de acordo com o clima (TATLI; DALFES, 2016). As zonas de vida de Holdridge divide o território com base em três variáveis, quais sejam, a precipitação total anual, a biotemperatura média anual e a relação de evapotranspiração potencial (YUE et al., 2001). A biotemperatura média anual é definida como a média das temperaturas em que o crescimento vegetativo é esperado $\left(0\right.$ a $\left.30^{\circ} \mathrm{C}\right)$, essa premissa parte do pressuposto que as plantas se tornam fisiologicamente inativas quando esses limites são ultrapassados (HOLDRIDGE, 2000). A relação de evapotranspiração potencial, por sua vez, representa um índice de aridez relacionado com as condições de umidade do ambiente (SISNEROS et al., 2011).

Importante destacar que, pelo fato do sistema de Holdridge reconhecer as respostas ecofisiológicas das plantas em função do balanço hídrico e energético, ele não representa apenas a cobertura vegetal potencial que pode ocorrer em determinado local, mas também define as condições de existência e funcionamento de cada zona de vida (HOLDRIDGE, 2000). Desse modo, a classificação de Holdridge é uma ferramenta útil para a gestão territorial dos recursos naturais, bem como para subsidiar a elaboração de estratégias e políticas públicas que resultem na definição de áreas prioritárias para conservação e no uso sustentável das florestas.

Embora esteja majoritariamente sob a influência de um macroclima semiárido, o estado do Ceará apresenta em função de fatores geográficos locais, como a altitude e a proximidade do oceano (SILVA; CAVALCANTE, 2004), gradientes de umidade que se alteram consideravelmente, condicionando a ocorrência de significativa heterogeneidade paisagística (MORO et al., 2015). A região costeira e as serras, por exemplo, recebem mais precipitação do que a depressão sertaneja (NIMER, 1972), configurando encraves vegetacionais diferenciados daqueles encontrados no sertão seco do interior do estado.

Portanto, a classificação do estado do Ceará como um território ambientalmente homogêneo, tal como acontece quando é adotado o conceito de biomas, acaba generalizando algumas peculiaridades importantes dos ecossistemas. Desse modo, 
a classificação de Holdridge representa uma alternativa interessante de zoneamento ecológico, uma vez que reconhece com maior detalhamento a variação ambiental existente associada aos fatores bioclimáticos. Diante do exposto, os objetivos deste trabalho foram identificar e descrever as zonas de vida que ocorrem no estado do Ceará com base no modelo bioclimático de Holdridge.

\section{MATERIAL E MÉTODOS}

\subsection{Caracterização da área de estudo}

A área de estudo corresponde ao estado federativo do Ceará, que está inserido entre os paralelos $2,5^{\circ}$ e $8^{\circ}$ de latitude sul e os meridianos $37^{\circ}$ e $42^{\circ}$ de longitude oeste. Sua extensão territorial é de 148.886 quilômetros quadrados, composto por 184 municípios com população total de 8.452.381 habitantes (BRASIL, 2016).

De acordo com o "Mapa de Biomas do Brasil: primeira aproximação" (IBGE, 2004), o estado do Ceará é totalmente coberto por vegetação de Caatinga. Entretanto, no Ceará é possível encontrar outros tipos de vegetação, como Florestas Ombrófilas, Florestas Estacionais, Cerrados, além das Formações Pioneiras que ocorrem ao longo da costa litorânea (BRASIL, 2016).

De acordo com a classificação climática de Köppen, o território do Ceará apresenta dois tipos climáticos, quais sejam, As - clima tropical com verão seco (62,3\%) e BSh - clima semi-árido de baixa latitude e altitude (37,7\%) (Figura 1a) (ALVARES et al., 2014).

As características climáticas atualmente vigentes no Ceará notabilizam-se pelo predomínio de temperaturas médias do ar elevadas durante a maior parte do ano e uma pequena amplitude anual na temperatura média (Figura 1b), já que o estado é tipicamente quente o ano todo (MORO et al., 2015).

De maneira geral, os índices pluviométricos se distribuem de modo decrescente 
do litoral para o interior (Figura 1c), como consequência da menor influência dos ventos alísios sobre as regiões mais interiores (NIMER, 1972), onde as serras elevadas constituem paisagens de exceção na matriz semiárida.

No que diz respeito à geologia, o Ceará possui basicamente dois grandes domínios geológicos: um sedimentar e outro cristalino. Sobre esses domínios foram modelados diferentes tipos de relevo (MORO et al., 2015), nos quais as altitudes médias municipais variam aproximadamente entre $18 \mathrm{~m}$ e 800 m (Figura 1d).

Figura 1 - Caracterização da área de estudo

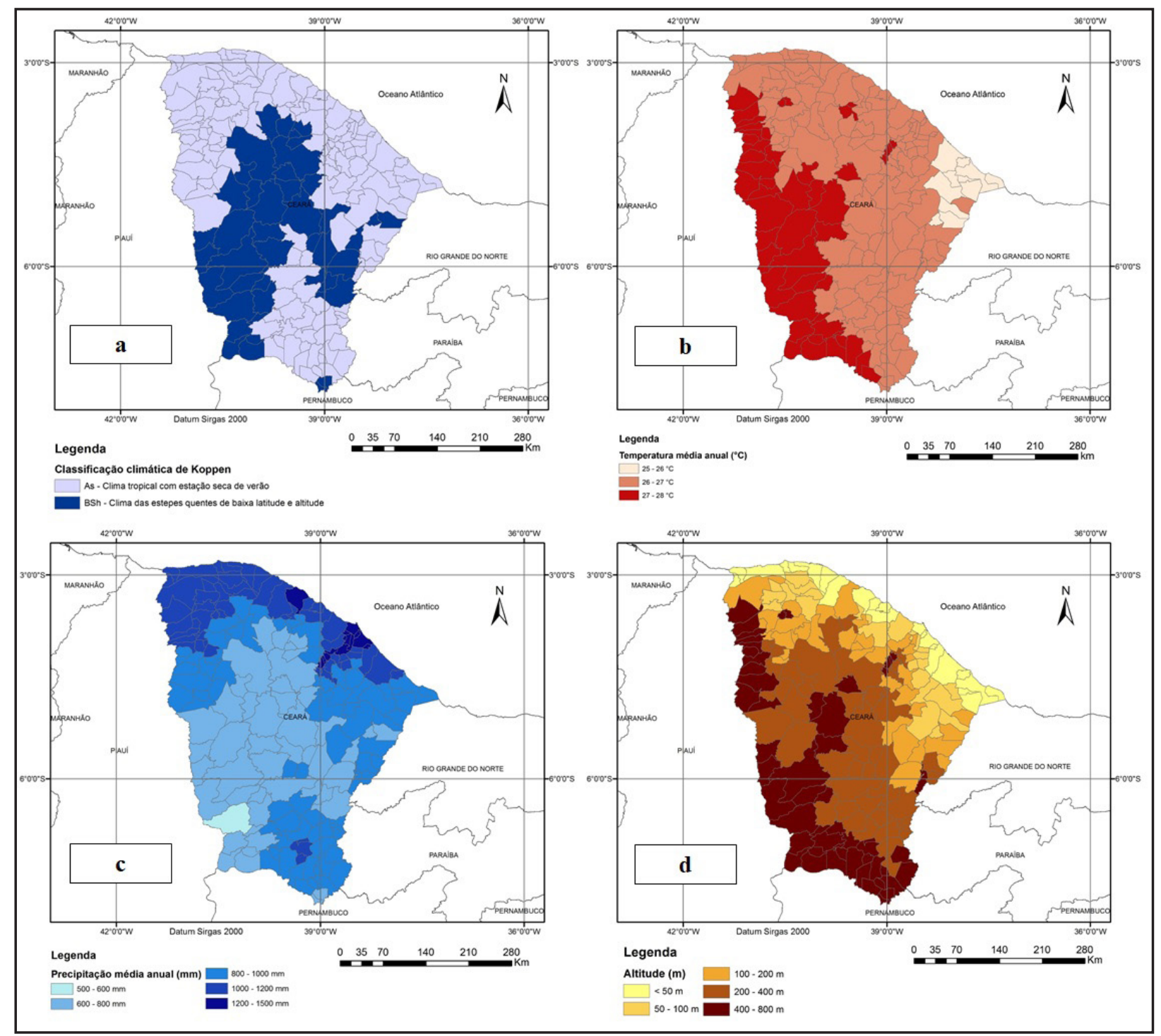

Fonte: Autores, baseado em Alvares et al. (2014) 


\subsection{Obtenção dos dados}

Os dados climáticos utilizados neste estudo foram fornecidos por Alvares et al. (2014), os quais compreendem registros de 2.950 estações meteorológicas para dados de precipitação e 2.400 para dados de temperatura, em um período nunca inferior a 25 anos de observações, entre os anos de 1950 e 1990. Os dados foram obtidos nas seguintes fontes: Instituto Nacional de Meteorologia (INMET), Departamento Nacional de Obras Contra as Secas (DNOCS) e Organização das Nações Unidas para Agricultura e Alimentação (FAO/ONU).

O banco de dados utilizado apresentava as informações de temperatura média mensal, precipitação mensal, altitude média e a classificação climática de Köppen para cada um dos 5.564 municípios brasileiros, dentre os quais foram selecionados os dados referentes aos 183 municípios do estado do Ceará. Sendo assim, neste estudo é apresentada a classificação de Holdridge por município devido à disponibilidade dos dados de Alvares et al. (2014) se apresentarem nessa escala.

Os dados de altitude utilizados por Alvares et al. (2014) foram obtidos a partir de um Modelo Digital de Elevação (DEM) fornecido pela Shuttle Radar Topography Mission (SRTM), com resolução espacial de 90 m. Em seguida, foi calculada uma altitude média para cada município.

\subsection{Processamento e análise dos dados}

Com a utilização dos dados de temperatura foi calculada a biotemperatura média anual (Tbio) para cada município. Entretanto, antes disso, as temperaturas acima de $24^{\circ} \mathrm{C}$ foram corrigidas, Equação (1), para que temperaturas acima de $30^{\circ} \mathrm{C}$, que eventualmente tenham ocorrido no período, sejam sistematicamente desconsideradas 
da média mensal, uma vez que o sistema de classificação de Holdridge estabelece que somente o intervalo de temperatura em que ocorre o efetivo crescimento das plantas (0 a $\left.30^{\circ} \mathrm{C}\right)$ deve ser avaliado.

$$
T_{\text {cor }}=T-\left[\frac{3 l}{100}-\left(T-24^{2}\right)\right]
$$

Em que: $T_{\text {cor }}=$ biotemperatura mensal corrigida $\left({ }^{\circ} \mathrm{C}\right) ; T=$ temperatura média mensal $\left({ }^{\circ} \mathrm{C}\right) ;$ $l=$ latitude.

Após a correção das biotemperaturas mensais, foi calculada a $T_{\text {bio }}$ para cada município, Equação (2).

$$
T_{\text {bio }}=\frac{\sum_{i=1}^{12} T_{\text {cor }}>0^{\circ} \mathrm{C}}{12}
$$

Em que: $T_{\text {bio }}=$ biotemperatura média anual.

Com os dados de $T_{\text {bio' }}$ foi calculada a evapotranspiração total anual (ETP) para cada município, Equação (3).

$$
E T P=58,93 \cdot T_{b i o}
$$

Em que: $E T P=$ potencial de evapotranspiração total anual $(\mathrm{mm})$.

Após a obtenção dos dados de evapotranspiração total anual para cada município, foi calculada a relação de evapotranspiração potencial $\left(R_{e t p}\right)$, por meio da divisão entre o potencial de evapotranspiração total anual e a precipitação total anual (PPT), Equação (4).

$$
R_{\text {etp }}=\frac{E T P}{P P T}
$$

Em que: $R_{\text {etp }}=$ Relação de evapotranspiração potencial; $E T P=$ potencial de evapotranspiração total anual $(\mathrm{mm}) ; P P T=$ precipitação total anual $(\mathrm{mm})$.

Por fim, a partir do cálculo da biotemperatura, juntamente com a precipitação, a relação de evapotranspiração potencial e a determinação da região latitudinal e 
dos pisos altitudinais, foi possível, com o auxílio dos diagramas de classificação de Holdridge (HOLDRIDGE, 2000), determinar as zonas de vida dos municípios no estado do Ceará, conforme demonstrado na Figura 2.

Figura 2 - Fluxograma dos processos relacionados à classificação climática de Holdridge

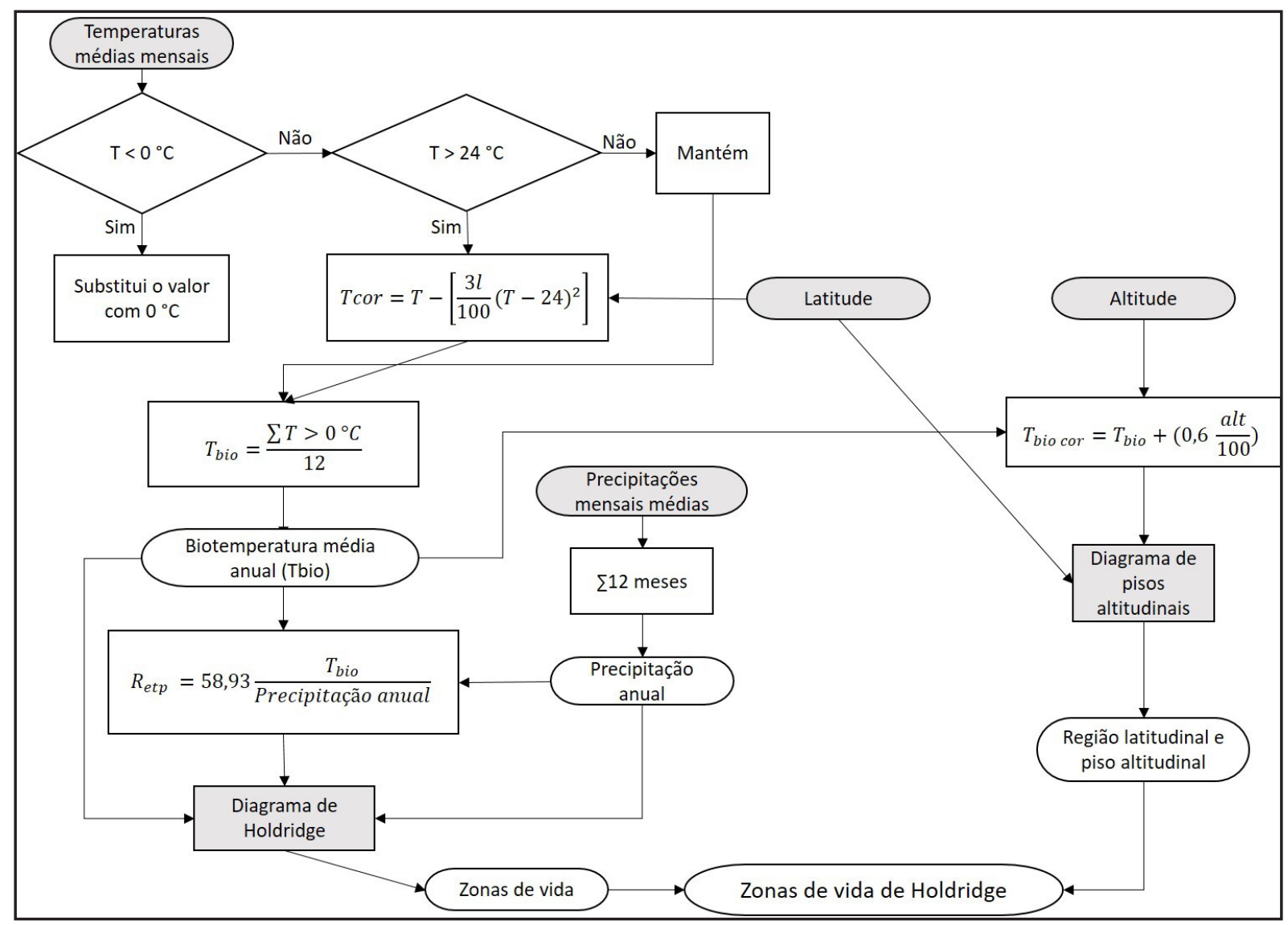

Fonte: Adaptado de Tres et al. (2020).

\section{RESULTADOS E DISCUSSÃO}

A classificação climática de Holdridge identificou oito zonas de vida para o estado do Ceará (Figura 3), em que todas pertencem à faixa latitudinal tropical e abrangem faixas altitudinais basais $(90,04 \%$ do território cearense) e premontanas $(9,96 \%)$ que variam, em termos de umidade, desde florestas muito secas até florestas úmidas. 
Figura 3 - Zoneamento bioclimático do estado do Ceará sensu Holdridge

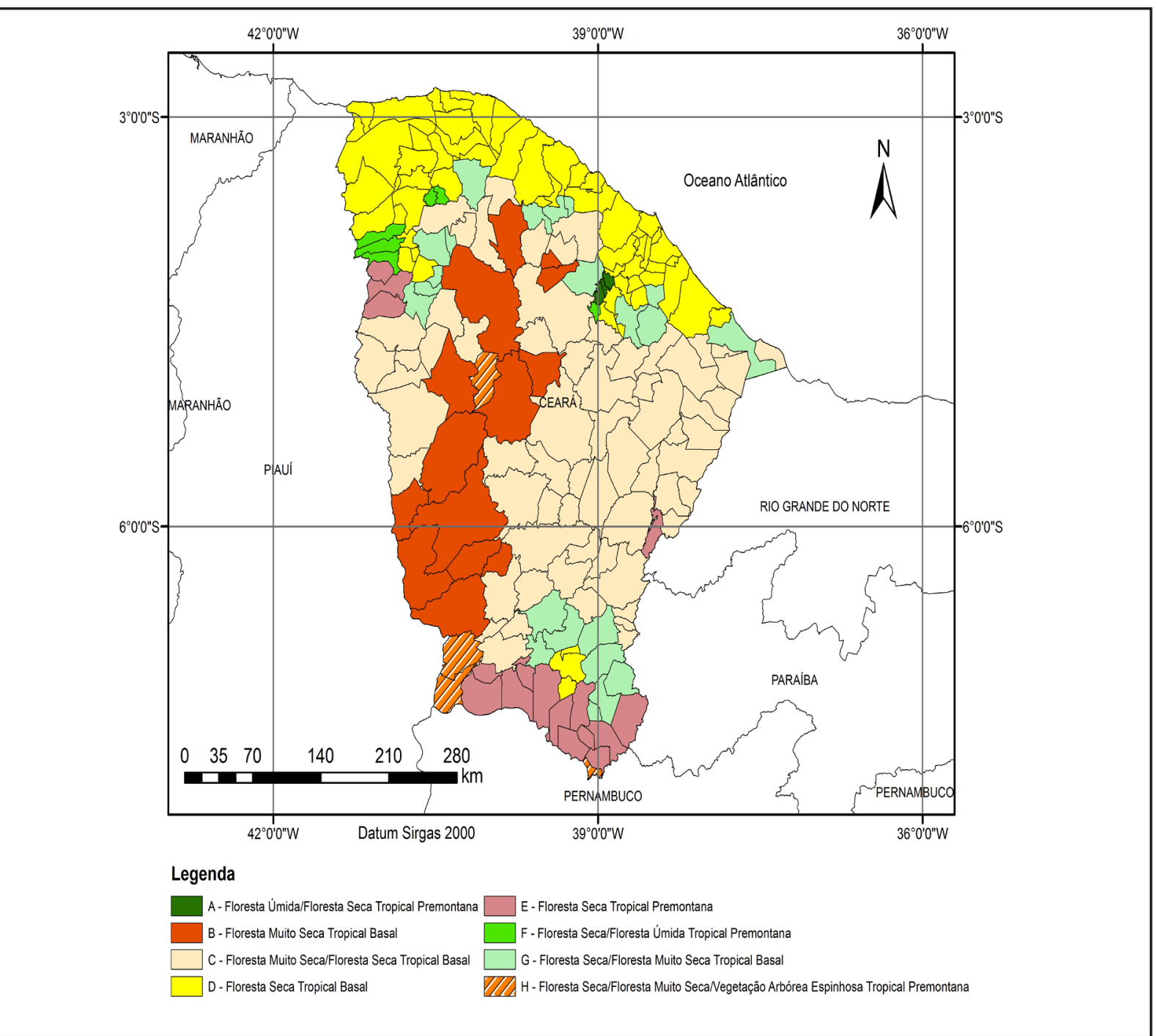

Fonte: Autores (2020)

A zona de vida de transição entre floresta úmida e floresta seca tropical premontana (A) foi a que apresentou a menor cobertura territorial, ocupando área de $305,10 \mathrm{~km}^{2}$ equivalente a 0,21\% da área total do estado. Essa zona de vida corresponde às formações denominadas como "matas úmidas". Por outro lado, as formações denominadas como "matas secas" possuem correspondência ao que o presente estudo classificou como zona de vida de transição entre floresta seca e floresta úmida tropical premontana (F), a qual ocupa área de $1.576,10 \mathrm{~km}^{2}$ equivalente a 1,06\% da área total do estado (vide Tabela 1). 
Tabela 1 - Área total coberta pelas zonas de vida de Holdridge no estado Ceará

\begin{tabular}{lcc}
\hline \multicolumn{1}{c}{ Zonas de vida } & Área $\left(\mathbf{k m}^{\mathbf{2}}\right)$ & \% da área total \\
\hline A - Floresta Úmida/Floresta Seca Tropical Premontana & 305,10 & 0,21 \\
B - Floresta Muito Seca Tropical Basal & $26.821,06$ & 18,01 \\
C - Floresta Muito Seca/Floresta Seca Tropical Basal & $64.825,69$ & 43,54 \\
D - Floresta Seca Tropical Basal & $29.094,94$ & 19,54 \\
E - Floresta Seca Tropical Premontana & $10.021,63$ & 6,73 \\
F - Floresta Seca/Floresta Úmida Tropical Premontana & $1.576,10$ & 1,06 \\
G - Floresta Seca/Floresta Muito Seca Tropical Basal & $13.321,28$ & 8,95 \\
H - Floresta Seca/Floresta Muito Seca/Vegetação Arbórea & & 1,96 \\
Espinhosa Tropical Premontana & $2.920,20$ & 100 \\
\hline Total & & $148.886,00$ \\
\hline
\end{tabular}

Fonte: Autores (2020)

Segundo Moro et al. (2015), as "matas úmidas" ocorrem no barlavento dos maciços residuais (serras) mais altos do Ceará e são frequentemente descritas na literatura como "brejos de altitude". A ocorrência das "matas úmidas" se deve ao fato das serras mais altas barrarem o vento úmido que vem do oceano e forçarem a elevação e a condensação das massas de ar, fazendo com que a face da serra voltada para o mar (barlavento) receba uma quantidade de chuvas bem superior à que é precipitada nas áreas adjacentes. Enquanto uma maior quantidade de chuvas nas partes altas do barlavento das serras permite o desenvolvimento das "matas úmidas", o sotavento das mesmas serras e as cotas altitudinais mais baixas recebem uma quantidade menor de chuvas, ocorrendo nessas áreas o tipo vegetacional denominado de "matas secas".

As zonas A e F estão classificadas em locais onde a Retp é menor ou igual a 1,687, a Tbio é menor ou igual a $23,979{ }^{\circ} \mathrm{C}$ e a PPT é superior a 997,466 mm (Figura 4). 
Figura 4 - Árvore de classificação utilizada para identificar as condições de ocorrência de cada zona de vida com base em variáveis bioclimáticas

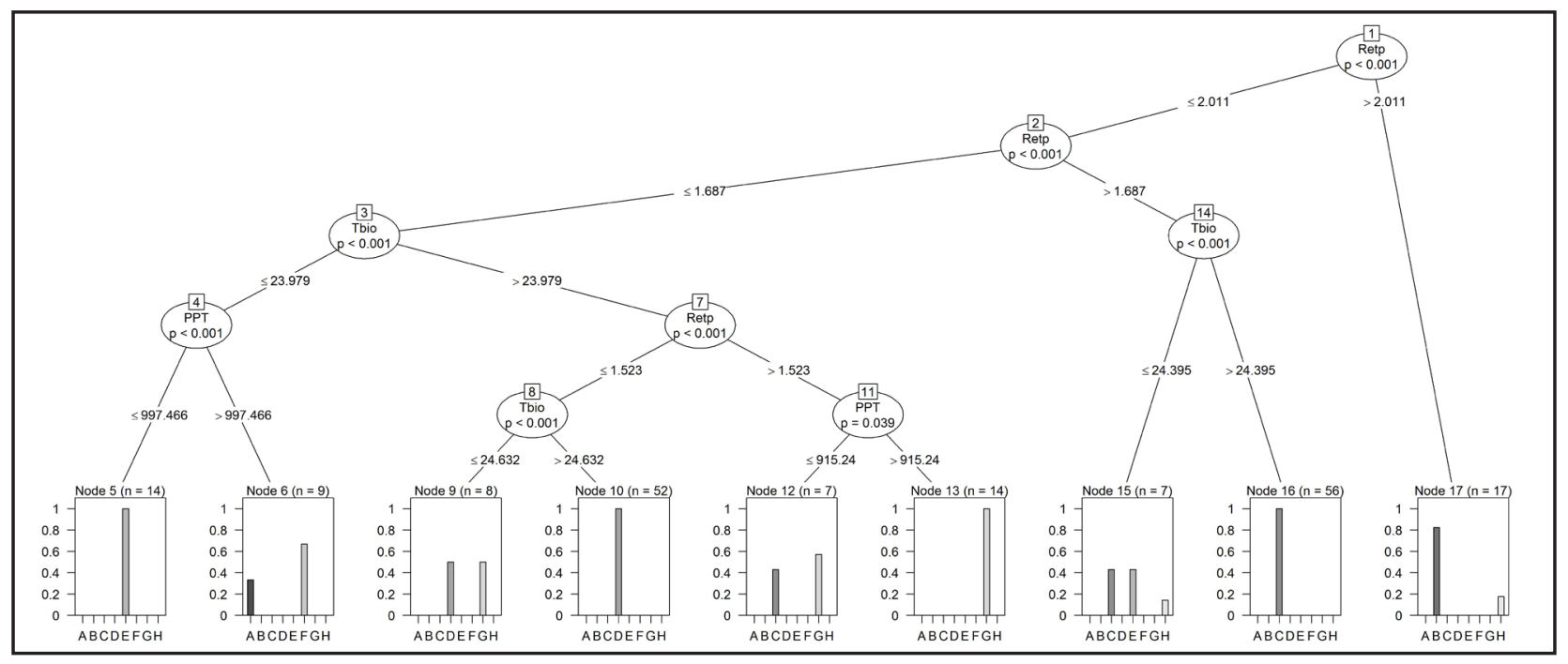

Fonte: Autores (2020)

Em que: $\mathrm{A}$ = floresta úmida/floresta seca tropical premontana; $\mathrm{B}$ = floresta muito seca tropical basal; $\mathrm{C}=$ floresta muito seca/floresta seca tropical basal; $\mathrm{D}=$ floresta seca tropical basal; $\mathrm{E}=$ floresta seca tropical premontana; $\mathrm{F}$ = floresta seca/floresta úmida tropical premontana; $\mathrm{G}=$ floresta seca/floresta muito seca tropical basal; $\mathrm{H}$ = floresta seca/floresta muito seca/vegetação arbórea espinhosa tropical premontana.

A zona de vida mais extensa do estado do Ceará foi a transição entre floresta muito seca e floresta seca tropical basal (C), ocupando área de $64.825,69 \mathrm{~km}^{2}$, seguida por floresta seca tropical basal (D), com 29.094,94 km², e floresta muito seca tropical basal (B), com 26.821,06 km². Juntas essas três zonas de vida corresponderam a 81,09\% do território estadual.

A área ocupada pelas zonas de vida B e C corresponde, em sua maior parte, à unidade fitoecológica denominada por Moro et al. (2015) como caatinga do cristalino, que é a vegetação típica que ocorre na Depressão Sertaneja e ocupa níveis altimétricos majoritariamente inferiores a $400 \mathrm{~m}$. Por outro lado, as porções mais elevadas da Depressão Sertaneja foram classificadas no presente estudo como transição entre floresta seca e floresta muito seca e vegetação arbórea espinhosa tropical premontana (H), ocupando área de $2.920,20$ km², equivalente a 1,96\% do território do estado. 
Além de ocorrer em cotas altitudinais relativamente elevadas (Figura 5d), a zona de vida $\mathrm{H}$ é caracterizada por apresentar valores moderados de Tbio, diferentemente das zonas B e C, que apresentaram valores elevados (Figura 5c). Além disso, a zona de vida $\mathrm{H}$ apresenta baixos valores de PPT, o que também é observado para as zonas de vida B e C (Figura 5b). Entretanto, o principal condicionante ambiental para a ocorrência da zona H são os elevados valores de Retp (Retp > 2,011) (Figura 5a).

Figura 5 - Valores das variáveis ambientais Retp (a), PPT (b), Tbio (c) e altitude (d) utilizadas para a classificação bioclimática do Ceará segundo o diagrama de classificação de Holdridge, com os desvios-padrão indicados na forma de box plots

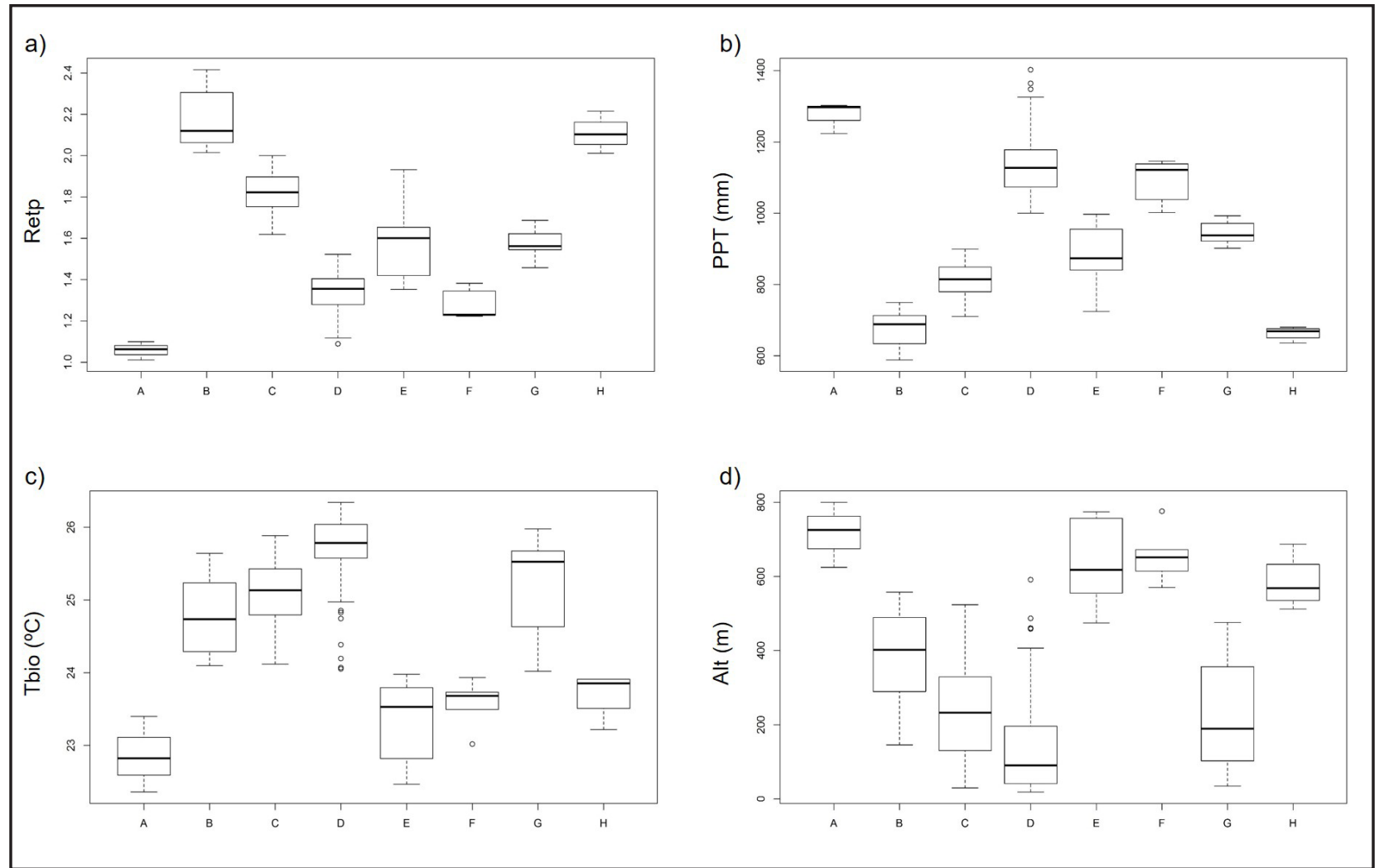

Fonte: Autores (2020)

Em que: $\mathrm{A}$ = floresta úmida/floresta seca tropical premontana; $\mathrm{B}=$ floresta muito seca tropical basal; $\mathrm{C}=$ floresta muito seca/floresta seca tropical basal; $D$ = floresta seca tropical basal; $E$ = floresta seca tropical premontana; $\mathrm{F}$ = floresta seca/floresta úmida tropical premontana; $\mathrm{G}$ = floresta seca/floresta muito seca tropical basal; $\mathrm{H}$ = floresta seca/floresta muito seca/vegetação arbórea espinhosa tropical premontana. 
A ocorrência em áreas de elevados valores de Retp não é uma característica exclusiva da zona de vida H. Destaca-se que o principal condicionante para a ocorrência da zona de vida B também foi a Retp maior que 2,011, demonstrando que essas duas zonas de vida representam as áreas de maior déficit hídrico no estado do Ceará.

A zona de vida floresta seca tropical basal (D) ocorre em uma área de 29.094,94 km², equivalente a 19,54\% do território do Ceará. Essa zona de vida corresponde, na maioria dos casos, ao que Figueiredo (1997) denominou de ‘Complexo Vegetacional da Zona Litorânea', que abrange a planície litorânea em uma faixa contínua na orla marítima entre o mar e os tabuleiros costeiros.

A zona de vida D ocorre preferencialmente em áreas que apresentam Tbio elevada (Tbio $>24,632{ }^{\circ} \mathrm{C}$ ) e de baixa Retp (Retp $\left.\leq 1,523\right)$. Outra característica marcante é que por estar, na maioria dos casos, localizada próxima ao mar, a zona de vida D apresenta elevados valores de PPT, fato que contribui para que a Retp seja baixa, pois é a zona de vida que apresenta a Tbio mais elevada no estado. Outro fato interessante é que a zona de vida $D$ também se apresentou em áreas disjuntas próximas à Chapada do Araripe no sul do estado. Em relação às áreas de zona de vida D no sul do estado, essas áreas apresentaram a particularidade de ocorrer em locais com Tbio $\leq 24,632^{\circ} \mathrm{C}$.

A zona de vida floresta seca tropical premontana (E) ocupa área de 10.021,63 $\mathrm{km}^{2}$, equivalente a 6,73\% do estado do Ceará e corresponde, em parte, ao que Moro et al. (2015) denominaram de caatinga do sedimentar, que é regionalmente chamada de "carrasco". Esse tipo de vegetação trata-se de uma vegetação decídua e não espinhosa que ocorre nas bacias sedimentares do Nordeste. Além disso, a zona de vida E também possui correspondência com as áreas de cerrados e cerradões interiores localizados no sul do estado, na região da Chapada do Araripe. A zona de vida E ocorre exclusivamente em locais onde a Retp é menor ou igual a 1,687, a Tbio é menor ou igual a $23,979^{\circ} \mathrm{C}$ e a PPT é inferior ou igual a 997,466 mm.

Uma diferença estrutural marcante entre as caatingas do sedimentar e do 
cristalino é que nas áreas sedimentares a proporção de espécies herbáceas na comunidade é bem menor que nas áreas cristalinas (MORO, 2013). Uma síntese recente demonstrou que, enquanto nas áreas cristalinas os terófitos são a forma de vida predominante, nas áreas sedimentares os fanerófitos são a forma de vida principal, embora também ocorra a presença de terófitos (MORO, 2013; MORO et al., 2014).

A zona de vida transição entre floresta seca e floresta muito seca tropical basal (G) ocupa área de 13.321,28 km², equivalente a 8,95\% do território do estado, e corresponde aos tabuleiros costeiros e disjunções interiores. São porções de relevos planos, intercalados com trechos suave-ondulados e apresentam uma amplitude altimétrica resultante, especialmente, da erosão dos rios. É importante destacar que nos tabuleiros livres da ação do fogo predominam formações de floresta semidecídua de médio porte que apresentam elementos florísticos tanto do Cerrado, como da Caatinga, Mata Atlântica e até mesmo da Amazônia (CASTRO; MORO; MENEZES, 2012). Nas áreas dos tabuleiros sujeitas a incêndios frequentes, a vegetação assume fisionomia savânica (MORO; CASTRO; ARAÚJO, 2011).

A zona de vida $G$ ocorre em duas condições ambientais distintas, uma mais interiorana associada a locais com níveis de PPT menor ou igual a 915,24 mm e outra costeira onde a PPT é maior que 915,24 mm. Além disso, como condição geral para a ocorrência dessa zona de vida, destaca-se a Tbio maior que $23,979{ }^{\circ} \mathrm{C}$ e a Retp maior que 1,523 e menor ou igual a 1,687.

Por fim, é importante destacar que em virtude do uso inadequado da terra, muitas áreas podem ser negativamente afetadas sob a pressão de ações antrópicas e apresentarem cobertura do solo in loco diferente do que é previsto pelo sistema. Desse modo, o esquema de classificação aqui proposto não representa a cobertura do solo atual e sim os tipos potenciais de vegetação que podem ocorrer em um determinado local de acordo com as condições climáticas predominantes. 


\section{CONCLUSÕES}

O zoneamento ecológico proposto neste estudo permitiu um reconhecimento detalhado da variação ambiental existente no estado do Ceará associada aos fatores bioclimáticos.

Foram identificadas oito zonas de vida, todas situadas na faixa latitudinal tropical e faixas altitudinais basais $(90,04 \%$ do território cearense) e premontanas $(9,96 \%)$ que variam, em termos de umidade, desde florestas muito secas até florestas úmidas.

A zona de vida mais extensa compreende as áreas de transição entre floresta muito seca e floresta seca tropical basal, ocupando $64.825,69 \mathrm{~km}^{2}$, que recobre $43,54 \%$ da área total do estado.

A variável bioclimática mais importante para a classificação das zonas de vida no estado do Ceará foi a relação de evapotranspiração potencial, que representa a quantidade de água que é transferida para a atmosfera em relação a quantidade de água que é precipitada em determinado local.

\section{REFERÊNCIAS}

ALVARES, C. A et al. Köppen's climate classification map for Brazil. Meteorologische Zeitschrift, Berlin, v. 22, n. 6, p. 711-728, 2014.

BRASIL. Ministério do Meio Ambiente. Ceará: inventário florestal nacional: principais resultados. Brasília: Serviço Florestal Brasileiro, 2016. 104 p.

CASTRO, A. S. F.; MORO, M. F.; MENEZES, M. O. T. O Complexo vegetacional da zona litorânea no Ceará: Pecém, São Gonçalo do Amarante. Acta Botanica Brasilica, Feira de Santana, v. 26, p. 108-124, 2012.

HOLDRIDGE, L. R. Ecologia basada en zonas de vida. San Jose: Instituto Interamericano de Cooperación para la Agricultura, 2000. 216 p.

IBGE. Mapa de Biomas do Brasil: primeira aproximação. Rio de Janeiro, 2004. Disponível em: https://ww2.ibge.gov.br/home/presidencia/noticias/21052004biomashtml.shtm. Acesso em: 01 jun. 2017.

ISAAC, C.; BOURQUE, C. P. A. Ecological life zones of Saint Lucia. Global Ecology \& Biogeography, [S. I.], v. 10, p. 549-566, 2001. 
LUGO, A. E. et al. The Holdridge life zones of the conterminous United States in relation to ecosystem mapping. Journal of Biogeography, [s. I.], v. 26, p. 1025-1038, 1999.

MORO, M. F. Síntese florística e biogeográfica do domínio fitogeográfico da Caatinga. 2013. Tese (Doutorado em Biologia Vegetal) - Universidade Estadual de Campinas, Campinas, 2013.

MORO, M. F.; CASTRO, A. S. F.; ARAÚJO, F. S. Composição florística e estrutura de um fragmento de vegetação savânica sobre os tabuleiros prélitorâneos na zona urbana de Fortaleza, Ceará. Rodriguésia, Rio de Janeiro, v. 62, p. 407-423, 2011.

MORO, M. F. et al. A catalogue of the vascular plants of the Caatinga Phytogeographical Domain: a synthesis of floristic and phytosociological surveys. Phytotaxa, [s. I.], v. 160, p. 1-118, 2014.

MORO, M. F. et al. Vegetação, unidades fitoecológicas e diversidade paisagística do estado do Ceará. Rodriguésia, Rio de Janeiro, v. 66, n. 3, p. 717-743, 2015.

NIMER, E. Climatologia da Região Nordeste do Brasil: introdução à climatologia dinâmica. Revista Brasileira de Geografia, Rio de Janeiro, v. 34, p. 3-51, 1972.

SILVA, J. B.; CAVALCANTE, T. C. Atlas escolar, Ceará: espaço geo-histórico e cultural. João Pessoa: Grafset, 2004. 200 p.

SISNEROS, R. et al. Visualizing Life Zone Boundary Sensitivities Across Climate Models and Temporal Spans. Procedia Computer Science, Amsterdam, v. 4, p. 1582-1591, 2011.

TATLI, H.; DALFES, H. N. Defining Holdridge's life zones over Turkey. International Journal of Climatology, Oxford, v. 36, n. 11, p. 3864-3872, 2016.

TRES, A. et al. Ecological life zones of Brazil. Floresta, Curitiba, PR, v. 50, n. 3, p. 1575-1584, 2020.

YUE, T. X. et al. Scenarios of major terrestrial ecosystems in China. Ecological Modelling, Amsterdam, v. 199, p. 363-376, 2006.

\section{Contribuição de Autoria}

\section{1 - Tiago de Souza Ferreira}

Engenheiro Florestal, Me., Doutorando

https://orcid.org/0000-0002-1836-625X•tiagoferreira@florestal.eng.br

Contribuição: Conceituação, Análise Formal, Investigação, Metodologia, Validação, Visualização de dados, Escrita - primeira redação, Escrita - revisão e edição 


\section{2 - Andressa Tres}

Engenheira Florestal, Ma., Doutoranda

https://orcid.org/0000-0001-8913-5160•tres.andressa@gmail.com

Contribuição: Conceituação, Curadoria de dados, Análise Formal, Obtenção de financiamento, Investigação, Metodologia, Administração do projeto, Recursos, Software, Supervisão, Validação, Visualização de dados, Escrita - primeira redação, Escrita - revisão e edição

\section{3 - Bruna Kovalsyki}

Engenheira Florestal, Ma., Doutoranda

https://orcid.org/0000-0002-1213-2102•kovalsyki.b@gmail.com

Contribuição: Análise Formal, Investigação, Metodologia, Validação, Visualização de dados, Escrita - primeira redação, Escrita - revisão e edição

\section{4 - João Francisco Labres dos Santos}

Engenheiro Florestal, Me., Doutorando

https://orcid.org/0000-0001-5517-1868•joaolabres@ufpr.br

Contribuição: Análise Formal, Investigação, Metodologia, Validação, Visualização de dados, Escrita - primeira redação, Escrita - revisão e edição

\section{5 - Alexandre França Tetto}

Engenheiro Florestal, Dr., Professor

https://orcid.org/0000-0003-2251-964X·tetto@ufpr.br

Contribuição: Conceituação, Curadoria de dados, Análise Formal, Obtenção de financiamento, Investigação, Metodologia, Administração do projeto, Recursos, Software, Supervisão, Validação, Visualização de dados, Escrita - primeira redação, Escrita - revisão e edição

\section{6 - Ronaldo Viana Soares}

Engenheiro Florestal, PhD., Professor

https://orcid.org/0000-0002-8625-425X·rvsoares@ufpr.br

Contribuição: Supervisão, Escrita - revisão e edição

\section{7 - Willian Thomaz Wendling}

Engenheiro Florestal, Dr., Professor

https://orcid.org/0000-0002-9704-5437•wendling@ufpr.br

Contribuição: Conceituação, Metodologia, Software, Supervisão, Validação, Visualização de dados, Escrita - revisão e edição 


\section{8 - Antônio Carlos Batista}

Engenheiro Florestal, Dr., Professor

https://orcid.org/0000-0001-5929-3838•batistaufpr@ufpr.br

Contribuição: Supervisão, Escrita - revisão e edição

\section{Como citar este artigo}

Ferreira, T. S.; Tres, A.; Kovalsyki, B.; Santos, J. F. L.; Tetto, A. F.; Soares, R. V.; Wendling, W. T.; Batista, A. C. As zonas de vida baseadas em condições bioclimáticas no estado do Ceará, Brasil. Ciência Florestal, Santa Maria, v. 31, n. 3, p. 1240-1257, 2021. DOI 10.5902/1980509836756. Disponível em: https://doi.org/10.5902/1980509836756. Acesso em: xx mês-abreviado. 2021. 